\title{
Ensino de lógica de programação no ensino fundamental utilizando o jogo Robotizen: um relato de experiência
}

\author{
Igor Ferreira Dantas ${ }^{1}$, Jose Falcão de Araújo Neto ${ }^{1}$, Lucas Emanuel Santos da \\ Silva $^{1}$, Lourival Fragoso Bonfim Neto ${ }^{1}$, Douglas Henrique Emiliano de Oliveira \\ Lima $^{1}$, Pasqueline Dantas Scaico ${ }^{1}$, Thaíse Kelly de Lima Costa ${ }^{1}$ \\ ${ }^{1}$ Departamento de Ciências Exatas - Centro de Ciências Aplicadas e Educação - \\ Universidade Federal da Paraíba(UFPB) - João Pessoa, PB - Brazil \\ \{igor.ferreira, jose.falcao, lucas.emanuel, lourival.fragoso, douglas.emil \\ iano, pasqueline, thaise\}@dce.ufpb.br
}

\begin{abstract}
This paper reports an experience of undergratuate students teaching children in an elementary school basic concepts of programming. Aiming to set up an attractive and fun learning context, it was used an educational game named Robotizen. Its game design while enhance the experience of learning to code during the gameplay, also allowed researchers to come up with several new instructional strategies. The project was driven by a method that took in account stages of cognitive development of participants. Also, in strategically splitting the levels of Robotizen to achieve an iterative and collaborative model of learning. Results suggests how potential is this game to engage and provide an environment to learn interest and discovery-driven.
\end{abstract}

Resumo. Este artigo relata a experiência de licenciandos em Computação em ensinar lógica de programação no ensino fundamental. Visando estabelecer um contexto de aprendizagem lúdico e atraente, foi utilizado um jogo educativo digital, denominado Robotizen. O seu game design favorece a experiência de aprender a programar jogando e foi a base para novas estratégias didáticas. A metodologia do projeto guiou-se pelas fases de desenvolvimento cognitivo das crianças e na divisão estratégica dos cenários do Robotizen, a fim de introduzir e fazê-las utilizar conceitos de programação de forma iterativa e colaborativa. Os resultados obtidos sugerem o potencial do uso do jogo para engajar e estabelecer aprendizagem orientada a interesses e descobertas.

\section{Introdução}

A possibilidade de participar de novas experiências de aprendizagem viabilizadas através das lentes das tecnologias tem desmontado paulatinamente as fronteiras dos espaços formais de educação [Thomas e Brown 2011]. Na era digital, indubitavelmente, o universo dos jogos tem se tornado uma mídia central de entretenimento, mas também na qual se pode descobrir interesses e desenvolver competências.

Jogar é uma necessidade humana de se deslocar para universos imaginários [Huizinga 1971]. No caso de crianças, os jogos estabelecem formas de elas se manterem em contato com o lúdico e experimentar certo nível de controle nas suas decisões, o que torna o aprender um meio de descobertas. Gee (2003) considera o jogo por natureza uma engrenagem poderosa de aprendizagem, especialmente por ser um gatilho para despertar a imaginação que é estimulada quando se está engajado em uma experiência relevante. Um jogo é um mecanismo que valoriza a participação em negociações complexas, a interação, a investigação de situações hipotéticas, processos que culminam 
não apenas na diversão do jogador, mas que representam um sistema em que se é capaz de criar significado para o mundo.

Neste artigo, apresenta-se o detalhamento de um projeto de extensão voltado para crianças no ensino fundamental. $\mathrm{O}$ objetivo central foi o de apresentar conceitos básicos da lógica de programação. Por entender que o ensino de Computação na educação básica é essencial, assim como é aprender a ler e escrever, em concordância com o que afirma Resnik (2016), os autores deste trabalho vêm ao longo dos anos empenhando esforços em escolas públicas e experimentando diferentes abordagens de ensino. Nesta última, utilizou-se o jogo digital Robotizen, jogável em celulares e tablets. Apesar de o uso de jogos digitais ser matéria comum no ensino de programação para crianças, neste artigo, ao descrever a experiência com o uso desta mídia, espera-se ser possível disponibilizar elementos que guiem professores a replicar as atividades realizadas com as crianças.

O artigo está organizado da seguinte forma: a Seção 2 apresenta a metodologia do artigo, contextualizando a experiência do ensino de lógica de programação com princípios base que guiaram o planejamento e a divisão da atividade para o públicoalvo; a Seção 3 mostra detalhes do Robotizen, explicando enredo, cenário e lógica do jogo; a Seção 4 relata a aplicação do jogo, detalhando o ocorrido em cada sessão da atividade com as turmas; por fim, na Seção 5 são apresentadas as lições aprendidas por meio dessa experiência.

\section{Metodologia}

A fim de promover o desenvolvimento de habilidades, como o raciocínio lógico e pensamento computacional das crianças, fez-se importante entender os estágios de desenvolvimento cognitivo humano. Especialistas na área de Psicopedagogia foram incorporados à equipe para fortalecer esta discussão no projeto. Os autores tomaram como base a teoria de Piaget (1999) que explica quatro estágios de desenvolvimento, a saber: o sensório motor; pré-operatório; operatório-concreto e o operatório formal.

As crianças participantes do projeto tinham entre onze e doze anos. De acordo com Piaget, nessa fase elas se encontram no terceiro estágio do desenvolvimento. Nesse estágio ocorre o aparecimento das operações intelectuais concretas e dos sentimentos morais e sociais de cooperação. É nesse período em que o raciocínio lógico, a capacidade de discussão, o sentimento de justiça e a cooperação afloram, mesmo com a capacidade de abstração ainda limitada. Tal fato apoia a escolha do projeto pela utilização de uma experiência concreta lúdica para fundamentar os conhecimentos.

Adicionar o lúdico ao ensino não é uma prática recente. Professores e pesquisadores propõem o ensino baseado em ludicidade, no sentido de que podemos incluir brincadeiras no processo de ensino. Pereira e Sousa (2016) afirmam que brincadeiras são ferramentas excelentes para o processo pedagógico e que os professores devem usá-las em sala de aula. Porém, estes recursos podem ser usados para diversão, mas também como meio de construção de conhecimento [Scaico e de Queiroz 2017]. As brincadeiras têm um papel fundamental na vida das crianças e sua importância é ressaltada por Teixeira (2010). Segundo ela, é por meio das brincadeiras que as crianças aprendem uma série de fatores fundamentais para o aprendizado, tais quais, seguir regras, experimentar formas de comportamento, socialização e a descoberta do mundo a sua volta.

Lima e Souza (2015) dizem que todos apresentam o raciocínio lógico, porém, não são todos que conseguem utilizar essa habilidade. Assim, o pensamento lógico tem 
que ser constantemente trabalhado e desenvolvido durante toda vida. Das habilidades fundamentais para desenvolver esse raciocínio lógico está o ensino de algoritmos, com frequência o primeiro conceito abordado dentro de sala de aula. A combinação da teoria Piagetiana com a ludicidade do Robotizen foram fatores determinantes para poder cultivar um ambiente capaz de compreender a limitação de algumas crianças e exercitar de maneira adequada o seu raciocínio lógico.

A atividade desenvolvida com o jogo Robotizen foi aplicada com cinco turmas do quinto ano do ensino fundamental e ocorreu nas dependências da escola parceira. Foram necessárias 3 sessões com o jogo divididas em: aquecimento, aprendendo condições e estrutura de repetição.

Cada sessão buscou estimular o aprendizado e aplicação dos conteúdos por meio do trabalho em equipe. Assim, os alunos precisavam criar algoritmos em conjunto, promovendo a discussão para o alcance da solução. Nesse sentido, a aprendizagem foi promovida por meio de atividade que privilegiou a interação entre pessoas e a colaboração.

A fim de aumentar o desafio, a partir da segunda sessão foi adicionado um fator externo ao jogo: um tempo limite para executar cada cenário, baseado no nível de dificuldade da missão. Dessa forma, o debate em grupo e o controle do tempo deram um senso de urgência na forma de como desenvolver a estratégia para chegar ao objetivo. Detalhes do jogo e a forma de utilização são descritas nas Seções 3 e 4.

\section{O jogo Robotizen}

O Robotizen é um jogo digital com foco no ensino de lógica de programação para crianças. Ele dispõe de atividades interativas envolvidas em uma história interessante que permite as crianças aprenderem conceitos básicos de programação, como: sequência, comando, condição, evento e repetição (Mage Studio, 2019).

$\mathrm{O}$ enredo do jogo retrata os desafios do robô Tesla para salvar a cidade Mage. $\mathrm{O}$ Prof. Mad envia um robô Bull para roubar a fonte de energia da cidade, um cristal, deixando-a na escuridão. Assim, Tesla precisa vencer várias missões para recuperar o cristal. Cada missão é realizada em um cenário diferente, envolvendo um desafio específico. Para resolver o desafio, a criança precisa criar um algoritmo que ajude o robô a cumprir suas tarefas, completar a missão e avançar no jogo. Esse enredo permite que a criança assuma um papel determinante, tornado-se programador, responsável por conduzir Tesla e fazê-lo crescer dentro da partida.

Atualmente, o jogo possui 50 cenários desbloqueados dentre mais de 100 níveis ainda previstos pela Mage Studio. O nível de dificuldade das missões é crescente, buscando manter o interesse do jogador e apresentar novos comandos de forma gradativa. O jogo começa exigindo do jogador movimentos simples que são guiados por animações. Quanto mais avançada, mais complexo se torna o algoritmo para chegar no objetivo da fase, que leva em consideração qual tipo de movimento se deve usar e quanto de energia gastar para fazer o melhor caminho possível do robô. A cada dez fases um novo desafio é introduzido, bem como cenários diferentes ou condições para se completar o objetivo da rodada.

O sistema para construção do algoritmo é simples, utilizando o sequenciamento de comandos por meio de operações arrastar e soltar. A Figura 1 apresenta a disposição dos elementos em um cenário do jogo. 


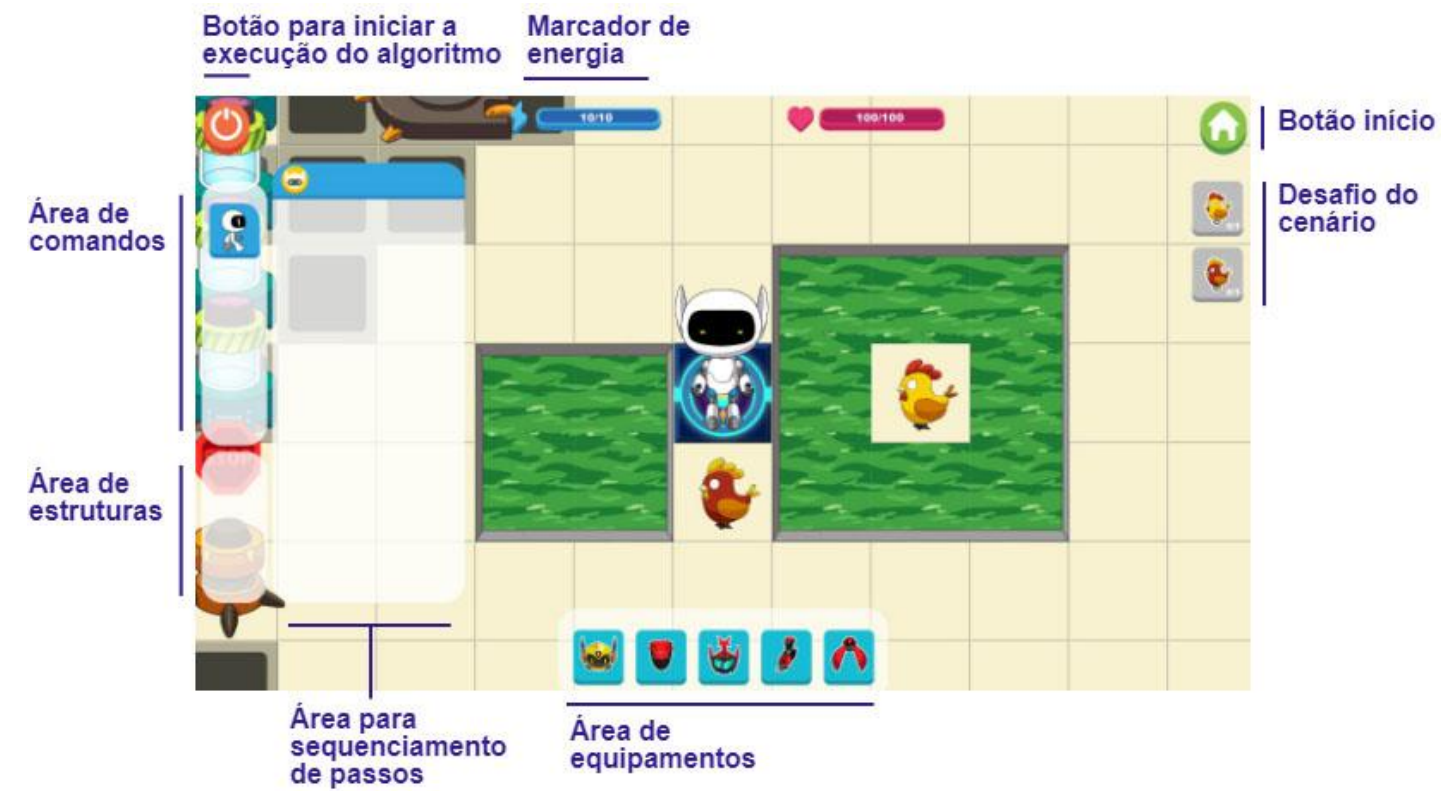

Figura 1. Disposição dos elementos em um cenário do jogo Robotizen. Fonte: Adaptado de Mage Studio (2019).

Novos equipamentos surgem para o Tesla a medida que avança o jogo. Esses equipamentos habilitam comandos ou estruturas antes não disponíveis, úteis para ajudar o robô a superar objetivos de forma mais eficiente (Figura 2). Os comandos com os quais é possível controlar o robô são: caminhar, coletar, voar, acelerar. Já como estruturas, tem-se a de repetição e condição.

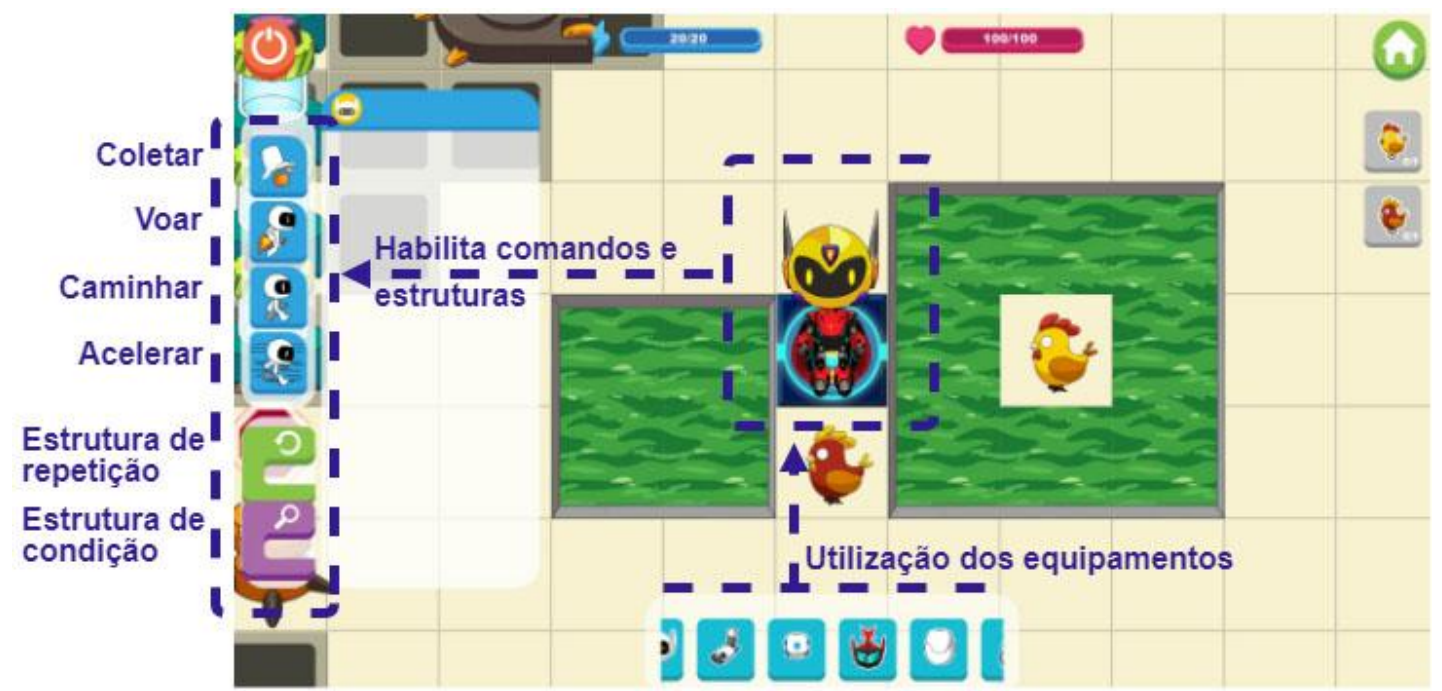

Figura 2. Habilitação de comandos e estruturas por meio do uso de equipamentos. Fonte: Adaptado de Mage Studio (2019).

\section{Detalhamento das atividades realizadas com o Robotizen}

A atividade com o Robotizen foi aplicada em uma sala livre da escola e cada turma era conduzida ao ambiente no seu horário de aula. Foram realizadas três sessões de atividades com o jogo. Na sala, foram dispostas mesas de apoio, a fim de centralizar as discussões dos grupos e a execução dos desafios (Figura 3). 


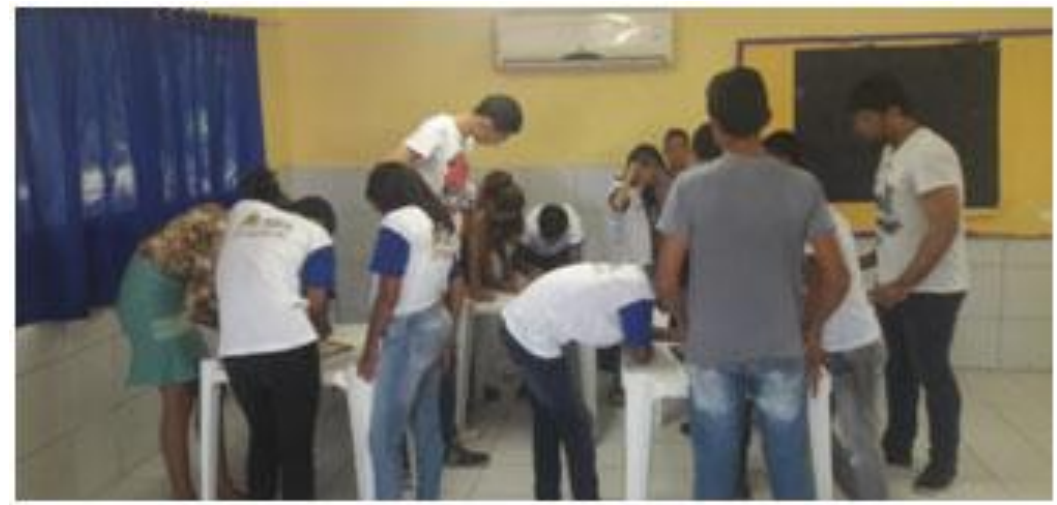

Figura 3. Divisão das equipes no ambiente. Fonte: próprio autor.

Os materiais utilizados constam ilustrados na Figura 4. Ei-los:

A. Computador, projetor e caixa de som: para exibição do jogo em momentos de apresentação dos desafios e discussão geral de resultados;

B. Placas (impressas), contendo os comandos, que eram usadas para demonstração da mecânica e sintaxe do jogo;

C. Comandos em papel e bases para comandos: utilizados para a montagem dos algoritmos de forma colaborativa em cada equipe;

D. Tablets: para os grupos testarem os algoritmos na equipe;

E. Placas de pontos: elementos sinalizadores do cumprimento de desafios, estimulando o avanço no jogo entre os grupos.

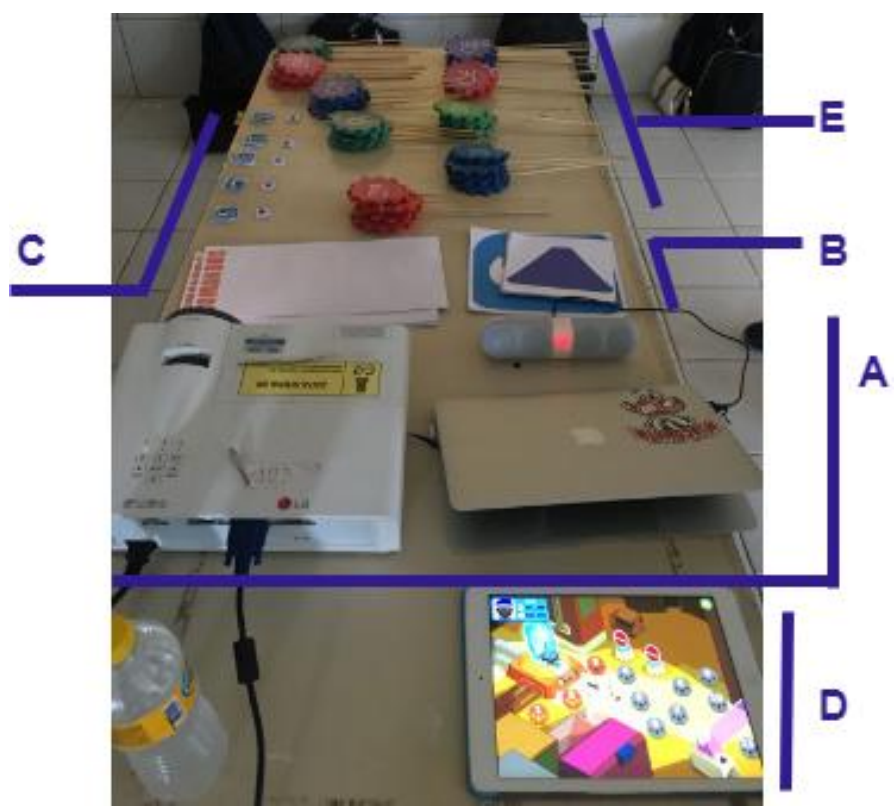

Figura 4. Materiais utilizados na atividade. Fonte: próprio autor.

\subsection{Primeira sessão com o Robotizen: o aquecimento}

Nessa sessão, ocorreu a apresentação do Robotizen. As crianças conheceram o enredo do jogo a fim de entender o sentido das ações executadas pelo robô Tesla e criar empatia com esse personagem principal. Elas também foram apresentadas aos comandos iniciais para criação dos algoritmos no jogo e aos primeiros desafios envolvendo a elaboração de sequência de passos. 
Os dez primeiros cenários do Robotizen foram explorados, cada qual com seu desafio. Nesses cenários, os desafios envolviam a construção de uma sequência de passos utilizando os comandos de caminhada e de direção (Quadro 1). A partir dos comandos, os grupos criavam algoritmos para ajudar o robô a chegar ao seu destino.

Quadro 1. Comandos explorados na primeira sessão com o Robotizen.

\begin{tabular}{|l|l|l|l|}
\hline \multicolumn{4}{|c|}{ Comandos de movimentação - gastos de energia: 1 ponto. } \\
\hline para direita & para cima & para esquerda & para baixo \\
\hline (1) & (1) & \\
\hline
\end{tabular}

Fonte: próprio autor.

A dinâmica para resolução do problema em cada cenário consistia em: (i) exibição do cenário e seu desafio para toda a turma; (ii) apresentação de comandos e conceitos, quando novos (a nível de turma); (iii) discussão e criação do algoritmo por equipe; (iv) teste da solução proposta em dispositivo móvel (por equipe); ( $v$ ) socialização das soluções algorítmicas com toda a turma; e (vi) explicação de erros e formas alternativas, quando necessário.

Em todas as turmas, aproximadamente a partir do sexto cenário, começaram a surgir entre as equipes diferentes algoritmos para a resolução do mesmo desafio. $\mathrm{O}$ fato ocorrido foi o ponto de partida para explicar às crianças formas alternativas para resolução de problemas e complexidade de algoritmos.

No robotizen, os comandos de caminhada consomem 1 ponto de energia do robô e este possui uma quantidade limitada de energia por cenário. Assim, as formas alternativas de algoritmos podem exercer influência no custo de energia e eficiência de execução. As crianças ao entenderem essas questões, começaram a buscar não apenas resolver os desafios, mas solucioná-los buscando baixo custo de energia e eficiência das soluções. A Figura 5 mostra uma equipe em processo de discussão e criação de algoritmo.

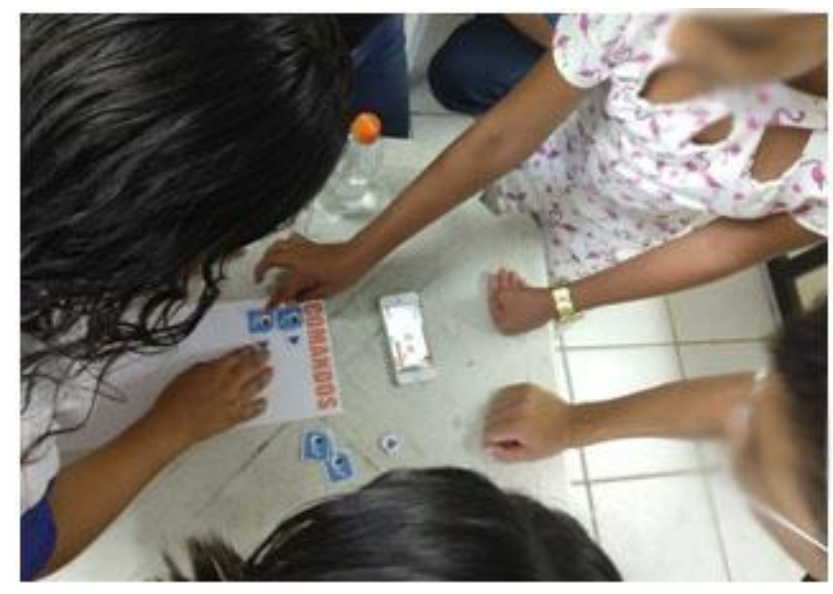

Figura 5. Elaboração de algoritmo em equipe. Fonte: próprio autor.

\subsection{Segunda sessão com o Robotizen: aprendendo condições}

Nessa sessão, foram explorados os cenários de 11 a 20. Com o objetivo de aumentar o desafio dos alunos no jogo, o mediador (licenciando em Computação) definia um tempo máximo para discussão, criação e teste do algoritmo em equipe. A definição do tempo variava de acordo com o nível de dificuldade do cenário, geralmente entre 45 segundos 
até 1 minuto e meio. O cronômetro para realização do desafio só era ativado após a apresentação do problema e da explicação dos comandos e conceitos novos.

Nos cenários, novos equipamentos podiam surgir para o robô e a utilização destes habilitava o aparecimento dos novos comandos (Quadro 2). Um dos comandos foi o coletar, que se tornava ativo quando o robô utilizava o braço robótico vermelho. $\mathrm{O}$ uso desse comando se fez necessário em cenários que desafiavam o jogador a conduzir o robô na coleta de galinhas espalhadas no local.

Quadro 2. Comandos explorados na segunda sessão com o Robotizen.

\begin{tabular}{|c|c|c|}
\hline Equipamento & Comando associado & Consumo de energia \\
\hline $\begin{array}{l}\text { Braço robótico } \\
\text { vermelho }\end{array}$ & 1 ponto \\
\hline $\begin{array}{l}\text { Asa robótica } \\
\text { vermelha }\end{array}$ & Coletar & 2 pontos \\
\hline
\end{tabular}

Fonte: próprio autor.

Quando os cenários apresentavam duas cores de galinha (amarela e vermelha), o comando de coleta oferecia ao jogador a possibilidade de escolha de cor, tornando possível explorar o conceito de condição (Figura 6). Nesse tipo de cenário, as crianças foram apresentadas a uma forma de seleção e aprenderam que o uso da instrução dentro do algoritmo diz ao robô que ele somente deve executar a coleta se a cor da galinha for satisfeita (condição).

Ao utilizar esse comando, as crianças também aprenderam que a definição incorreta de uma condição ocasionava erro no algoritmo. No caso do jogo, o robô manifestava a insatisfação com o erro transparecendo o sentimento de tristeza ou raiva. Quando o fato ocorria, a equipe depurava o algoritmo em busca do erro, corrigia-o e testava-o novamente.

O outro comando explorado na sessão foi o voar, que se tornava ativo quando o Tesla utilizava as asas robóticas vermelhas. $\mathrm{O}$ uso desse comando se fez necessário em cenários nos quais o jogador precisava que o robô sobrevoasse lagos ácidos, como o da Figura 6.

O comando voar, diferente dos demais apresentados até o momento, possuíam um gasto de energia equivalente a dois pontos. Dessa forma, as equipes precisavam estar atentas ao uso, pois este elevava o custo do algoritmo. Ao cumprir o desafio do cenário, o jogo avaliava o algoritmo executado em uma escala de 1 a 3 estrelas. Para conseguir as 3 estrelas, o algoritmo necessitava ser o melhor possível, ou seja, buscar o menor custo de energia e eficiência da solução. Diante deste fato, foi observado que as equipes, quando percebiam que sua solução algorítmica não alcançava as 3 estrelas, buscavam refazer a sequência de passos, analisando onde otimizar os gastos de energia. 


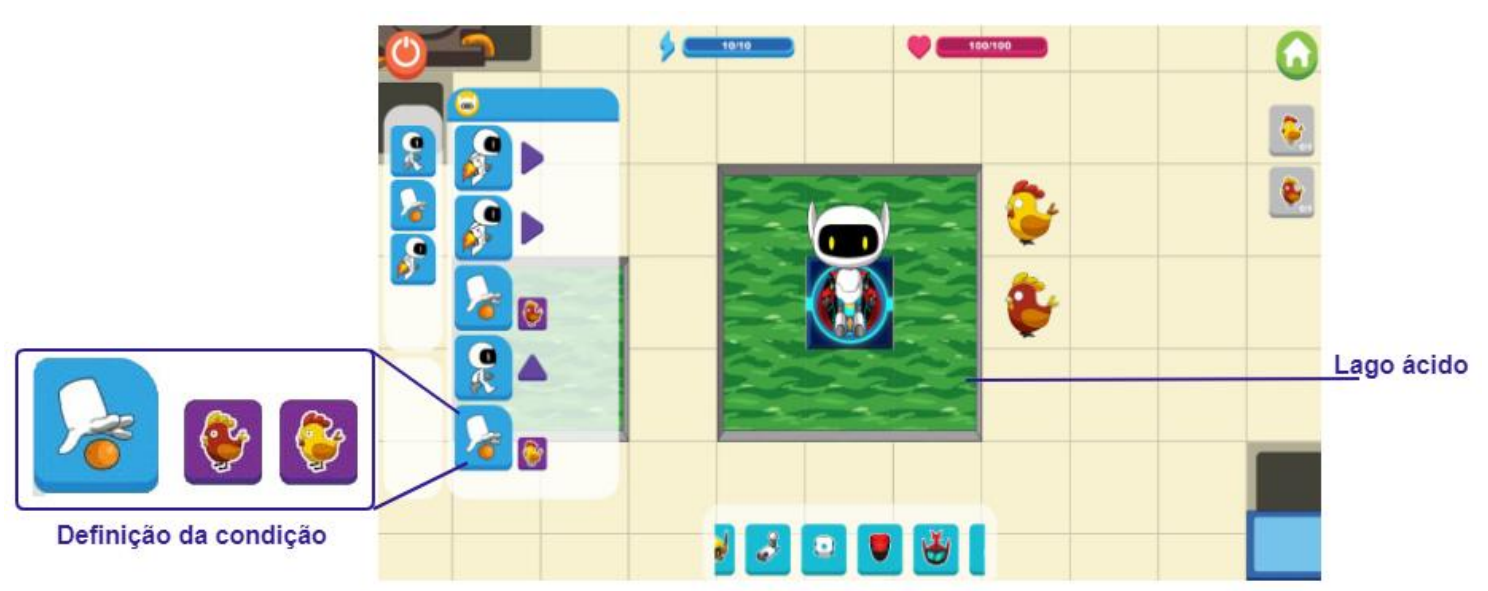

Figura 6. Exemplificação do comando de coleta condicional. Fonte: Adaptado de Mage Studio (2019).

\subsection{Terceira sessão com o Robotizen: estrutura de repetição}

Na última sessão foram explorados os cenários 26 ao 40 ou 47, dependendo da turma. Durante a sessão, vários alunos relataram que baixaram o jogo no celular para conseguirem utilizá-lo com mais frequência. Com esse treinamento voluntário entre a segunda e terceira sessão, observou-se uma maior rapidez na resolução dos desafios.

A partir do cenário 31, tornou-se possível o uso da estrutura de repetição, que ficava visível quando o robô utilizava o capacete vermelho (Quadro 3). Naquele momento, foi explicado e demonstrado aos alunos que o comando permitia que os jogadores criassem algoritmos mais compactos, mais legíveis e mais rápidos de serem desenvolvidos. Os alunos perceberam que podiam repetir até cinco vezes a mesma ação. No Robotizen, este número de vezes era representado por uma mão, que indicava o número de repetições, servindo como uma metáfora. Dessa forma, ao detectarem as vantagens de utilização dos laços de repetição para a resolução dos problemas, as equipes começaram a aplicar a estrutura em seus algoritmos.

Com a rápido avanço nos cenários, os alunos foram desafiados a voltarem aos estágios iniciais do jogo e refazerem os algoritmos utilizando a estrutura de repetição. A partir desse desafio, os alunos puderam compactar algoritmos anteriormente criados sem o conhecimento acerca dessa estrutura.

Quadro 3. Estrutura de repetição explorada na terceira sessão com o Robotizen.

\begin{tabular}{|c|c|}
\hline Equipamento & Estrutura \\
\hline Yy & $\begin{array}{l}\text { Capacete } \\
\text { vermelho }\end{array}$ \\
\hline
\end{tabular}

Fonte: próprio autor.

Ao concluírem o desafio e prosseguirem com o jogo durante a sessão, as crianças habilitaram o surgimento de outros equipamentos para o robô: a armadura vermelha e a perna robótica vermelha. A armadura vermelha proporcionou o aumento de energia do robô, essencial para a conclusão de alguns cenários. Já a perna robótica vermelha proporcionou aceleração do passo, também necessária em fases nas quais o robô passava a ser perseguido. Com os diferentes recursos e aumento dos desafios dos cenários, as crianças precisavam pensar em formas de resolver os problemas explorando 
o raciocínio lógico. Dessa forma, a evolução dos alunos na construção de algoritmos e lógica de programação foi evidenciada a partir do avanço nos cenários do jogo.

\section{Considerações finais}

Observa-se o crescimento de iniciativas para introduzir o ensino de programação para além de ambientes formais de ensino, rompendo as dificuldades da tradicional base nacional curricular. Algumas, tais como: CódigoKid ${ }^{1}$, Happy $\mathrm{Code}^{2}$, SuperGeeks $^{3}$ têm propostas inovadoras. Entretanto, alunos de escolas públicas são grupos menos favorecidos e dependem, muitas vezes, de projetos como este aqui descrito.

Esforços desta natureza são importantes, tanto por estabelecer oportunidades de crianças entrarem em contato com a Computação, quanto de demonstrar para professores que este é um projeto possível. Para os licenciandos em Computação, a experiência proporcionou o contato com a realidade local e com os desafios docentes na Educação Básica, como: manter a atenção e o foco de crianças no conteúdo, gerenciar tempo de aula e acompanhar o crescimento cognitivo em diferentes ritmos.

As sessões com o Robotizen favoreceram o trabalho em grupo dos alunos. As crianças eram estimuladas a concluir o desafio de cada cenário com a melhor performance possível, gastando a menor quantidade de energia. O debate entre grupos e o controle do tempo proviam um senso de urgência na forma de desenvolver a estratégia que utilizariam para chegar no objetivo. Com isso, tornou-se mais fácil apresentar novos conceitos.

O interesse e estímulo das crianças com a atividade foram observados empiricamente, por meio das reações das equipes ao cumprirem os desafios. Os alunos não apenas manifestavam satisfação por meio de gestos e frases positivas, como solicitavam de imediato a recompensa: a placa de pontos. As placas eram entregues às equipes que obtinham êxito no desafio do cenário, estimulando a continuidade no jogo.

Além disso, foi observado que os alunos não demonstravam dificuldade na continuação da atividade entre sessões, revelando que eram capazes de lembrar, compreender e aplicar o conceito de Algoritmos. O avanço e êxito nos quase 50 cenários abertos do jogo apontam o entendimento acerca de outros conceitos abordados, como condição e repetição.

A forma com que as sessões e atividades foram detalhadas neste artigo permite sua reprodução e adaptação para outros espaços educacionais. É importante relatar uma lição aprendida com a execução do projeto, sobretudo, porque a equipe queria "inovar" e levar para as crianças oportunidades de aprender conceitos iniciais sobre programação através de um recurso digital. Mas, como viabilizar a experiência sabendo da insuficiência da escola em oferecer tablets ou celulares para que as crianças pudessem jogar e aprender? Este cenário foi desafiador, e, como se sabe, ainda é realidade em muitas escolas públicas brasileiras. A primeira sessão, o Aquecimento, talvez tenha sido a mais complicada, uma vez que o plano original era o de projetar o jogo usando o único tablet que estava disponível. Apesar de parecer que as crianças estavam gostando da demonstração, elas demonstravam a vontade de manusear também o jogo. Para contornar esta limitação, a equipe concordou que cada membro do projeto - que estava responsável por um dos grupos - cederia (com supervisão) o seu próprio celular. Assim,

\footnotetext{
${ }^{1}$ https://www.codigokid.com.br/

$2 \mathrm{http} / / /$ www.happycodeschool.com

${ }^{3} \mathrm{http}: / /$ supergeeeks.com
} 
cada criança pode jogar uma rodada e ter um pouco da experiência do gameplay do jogo, algo que se percebeu ter sido determinante para as crianças entrarem em um ciclo virtuoso de aprendizagem e se manterem mais estimuladas a aprender.

Obviamente, em diferentes espaços de aprendizagem, adaptações diferentes merecem ser conduzidas dado a inúmeros fatores que tornam cada ambiente único. Contudo, a criatividade e a vontade de o educador fazer o que parece não ser possível, pode fazer a diferença. Espera-se que outros professores possam aplicar e refinar a experiência com seus alunos, e que este relato sirva como inspiração para que o ensino de Computação possa adentrar aos poucos nas escolas de educação básica.

\section{Referências}

Gee, J. P. The Anti-Education Era: Creating Smarter Students through Digital Learning, $1^{\text {st }}$ edition. Palgrave Macmillan, 2013.

Huizinga, J. Homo Ludens: A study of the play-element in culture. Boston: Beacon Press, 1971.

Lima, A. C., Souza, D. F. (2015) "Desenvolvimento do raciocínio lógico algoritmo na educação básica", In: II CONEDU - Congresso Nacional de Educação, Campina Grande - PB, Brasil.

Mage Studio. (2019) "Robotizen: Kids Learn Coding Robot", https://mage.com.vn/robotizen, Março.

Pereira, D. R. Souza, B. S. (2015) "A Contribuição dos jogos e brincadeiras no processo de ensino aprendizagem de crianças de um CMEI na cidade de Teresina", Revista Fundamentos, Teresina - PI, V.3, n.2.

Piaget, J. (1999) "Seis estudos de Psicologia", Tradução: Maria Alice Magalhães D’Amorim e Paulo Sérgio Lima Silva. 24a ed. Rio de Janeiro: Forense Universitária.

Resnik, M. “Designing for Wide Walls," Design Blog: MIT Scratch Team, MIT Media Lab, 2016.

Scaico, P. D. e de Queiroz, R. J. G. B. (2017) "Os jogos e a educação do futuro: o que estes universos têm a ver?", In Revista ELO, v. 24, p. 12-17.

Teixeira, S. R. O. (2010) "Jogos, brinquedos, brincadeiras e brinquedoteca: implicações no processo de aprendizagem e desenvolvimento", Rio de Janeiro: wak.

Thomas, D.; Brown, J. S. A New Culture of Learning : Cultivating the Imagination for a World of Constant Change, 1st edition, no. Summer. CreateSpace Independent Publishing Platform, 2011. 